\title{
Green tea polyphenol epigallocatechin 3-gallate in arthritis: progress and promise
}

\author{
Salahuddin Ahmed*
}

\begin{abstract}
Green tea's active ingredient, epigallocatechin 3-gallate (EGCG), has gained significant attention among scientists and has been one of the leading plant-derived molecules studied for its potential health benefits. In the present review I summarize the findings from some of the most significant preclinical studies with EGCG in arthritic diseases. The review also addresses the limitations of the dose, pharmacokinetics, and bioavailability of EGCG in experimental animals and findings related to the EGCG-drug interaction. Although these findings provide scientific evidence of the anti-rheumatic activity of EGCG, further preclinical studies are warranted before phase clinical trials could be initiated with confidence for patients with joint diseases.
\end{abstract}

\section{Rheumatoid arthritis and osteoarthritis: disease pathogenesis}

Rheumatoid arthritis (RA) is a chronic inflammatory disease characterized by the activation of synovial tissue lining the joint capsule, which results in the invasion of the cartilage and bone leading to the progressive joint dysfunction [1]. Severe morbidity and structural damage of joints caused by chronic inflammation often lead to major personal, family, and financial consequences, as well as increased mortality. Recent understanding of the RA pathogenesis has clarified the role of cytokines and other inflammatory mediators in this process and has provided a scientific rationale in the process of developing targeted therapies [2].

Osteoarthritis $(\mathrm{OA})$ is a common disorder of synovial joints characterized pathologically by focal areas of damage to the articular cartilage, centered on load-bearing

*Correspondence: Salah.Ahmed@utoledo.edu

Department of Pharmacology, 2232 Wolfe Hall, College of Pharmacy, 2801 W. Bancroft Street, Toledo, OH 43606, USA areas, which is associated with new bone formation at the joint margins (osteophytosis), changes in the subchondral bone, variable degrees of mild synovitis, and thickening of the joint capsule [3]. The severity of OA differs from patient to patient, but the very common clinical symptoms include pain, reduced range of motion, inflammation, and deformity [4]. This condition is strongly age related, being less common before the age of 40 but showing a marked increase in frequency with age [3]. Although OA is considered the disease of the destruction of articular cartilage, recent evidence suggests that it may also damage bone and synovium in the arthritic joints $[3,4]$. Despite existing evidence of the crosstalk between tissues at the cellular and molecular levels, however, intertwined pathophysiological processes causing OA have reduced the focus in choosing from one of these three tissues - articular cartilage, bone, or synovium - to serve as the key therapeutic target [3].

\section{Treatment of arthritis: approaches and options}

Conventional disease-modifying anti-rheumatic drugs such as methotrexate have long been the mainstay of RA treatment and are still advocated as a first-line option in newly diagnosed RA patients [5]. While a combination of good efficacy and acceptable toxicity, in conjunction with low cost and patient convenience, has made methotrexate an increasingly favored drug for RA, recent studies suggest that patients lose efficacy over time and only a minority of them achieve disease remission from its use [5]. TNF $\alpha$ inhibitors, as first-generation biologics, have radically changed the treatment of patients with refractory RA. Among patients with RA who are unresponsive to methotrexate, however, only two-thirds respond to TNF $\alpha$ inhibitors - which opened the option of combination therapy (combining disease-modifying anti-rheumatic drugs with biological therapy) [5,6]. As a result, newer approaches have resulted in the development of next-generation biologics during the past few years, including abatacept, rituximab, and tocilizumab $[2,6]$.

Pharmacological management of OA includes analgesics and nonsteroidal anti-inflammatory drugs. Unfortunately, these medications can precipitate severe adverse reactions while providing only symptomatic relief from pain and no 
effect on the progress of $\mathrm{OA}$ in some patients [7]. In addition, increased rates of cardiovascular events associated with cyclooxygenase-2 (COX-2) inhibitors and some conventional nonsteroidal anti-inflammatory drugs have made the treatments inappropriate for long-term use by OA patients with high risk of heart disease or stroke [8]. More recent emerging data from clinical trials conducted over nine clinical centers in the United States underlined the clinical efficacy of a glucosamine and chondroitin sulfate combination on the progressive loss of cartilage, pain, and stiffness in patients with knee OA [7].

\section{Plant-derived molecules for the treatment of arthritis}

The past decade or two have seen a dramatic increase and growing interest in the use of alternative treatments and herbal therapies by arthritis patients [9-11]. Trustworthy documentation of traditional knowledge, together with extensive modern scientific/pharmacological experimentation, however, is necessary to validate or refute the purported medicinal value. In this regard, epigallocatechin-3-gallate (EGCG) has in the past decade been extensively evaluated by us and other researchers for its potential anti-rheumatic activity using in vitro experimentations and animal models of arthritis. The following section of the present review highlights some of these major findings and puts forward an argument for the future development of EGCG as a potential therapeutic entity for rheumatic diseases.

\section{Epigallocatechin-3-gallate}

Green tea (Camellia sinensis) is one of the most commonly consumed beverages in the world and is a rich source of polyphenols known as catechins (30 to $36 \%$ of dry weight) including EGCG, which constitutes up to $63 \%$ of total catechins [12]. EGCG has been shown to be 25 to 100 times more potent than vitamins $\mathrm{C}$ and $\mathrm{E}$ in terms of antioxidant activity [13]. A cup of green tea typically provides 60 to $125 \mathrm{mg}$ catechins, including EGCG [14].

\section{Efficacy of EGCG in arthritis In vitro findings \\ Cartilage/chondrocyte protection}

Extensive studies in the past decade have verified the cartilage-preserving and chondroprotective action of EGCG. We pioneered research in this therapeutic area and studied the benefits of EGCG on progressive cartilage degradation, a hallmark of $\mathrm{OA}$, using chondrocytes derived from OA cartilage. Proinflammatory cytokines such as IL-1 $\beta$, TNF $\alpha$, and IL- 6 have been shown to modulate extracellular matrix turnover, to accelerate the degradation of cartilage, and to induce apoptosis in chondrocytes $[3,4]$.
Besides promoting imbalance between excessive cartilage destruction and cartilage repair processes, IL-1 $\beta$ has been a potent inducer of reactive oxygen species, including nitric oxide and inflammatory mediators such as prostaglandin $E_{2}$, via enhanced expression of the enzymes inducible nitric oxide synthase and COX-2, respectively $[15,16]$. Preincubation of human chondrocytes derived from OA cartilage at different micromolar concentrations of EGCG showed a marked inhibition in the IL-1 $\beta$-induced inducible nitric oxide synthase and COX-2 expression and activity, which further resulted in the reduced nitric oxide and prostaglandin $E_{2}$ synthesis $[15,16]$. Defining the molecular mechanism of EGCG's efficacy in regulating inducible nitric oxide synthase expression, the results showed that EGCG inhibits IL-1 $\beta$ induced phosphorylation and proteasomal degradation of IкB $\alpha$ to suppress NF-kB nuclear translocation [16].

In a follow-up study to determine the effect of EGCG on other signaling pathways triggered by IL- $1 \beta$, Singh and colleagues showed that EGCG selectively inhibited the $\mathrm{p} 46$ isoform of $\mathrm{c}-J u n-\mathrm{N}$-terminal kinase induced by IL-1 $\beta$ [17]. This resulted in the reduced accumulation of phosphorylated c-Jun and activation protein-1 DNA binding activity, and of activation protein-1-mediated inflammatory responses in OA chondrocytes.

Under normal circumstances, chondrocytes in the cartilage make extracellular matrix components such as aggrecan and type II collagen as required in response to mechanical pressure [3]. Under abnormal or diseased conditions, however, chondrocyte metabolism is altered under the influence of the increased influx of proinflammatory cytokines that activate matrix-degrading enzymes termed matrix metalloproteinases (MMPs) and of reactive mediators that promote cartilage degradation [18]. MMPs are a large group of enzymes that play a crucial role in tissue remodeling as well as in the destruction of cartilage in arthritic joints due to their ability to degrade a wide variety of extracellular matrix components $[19,20]$. Interestingly, the collagenases among the MMP family are of particular importance in joint disorders due to their ability to efficiently cleave type II collagen $[19,20]$.

In another study, we evaluated the potential of EGCG to protect human cartilage explants from IL- $1 \beta$-induced release of cartilage matrix proteoglycans and the induction and expression of MMP-1 and MMP-13 in human chondrocytes [21]. Our results showed that EGCG pretreatment of cultured human OA chondrocytes significantly inhibited the expression and activities of MMP-1 and MMP-13 in a dose-dependent manner [21]. In a parallel observation, another study found that catechins from green tea inhibited the degradation of human cartilage proteoglycan and type II collagen, and selectively inhibited ADAMTS-1, ADAMTS-4, and ADAMTS-5 [22,23]. Further evaluation of the effect of 
EGCG on the anabolic pathways in chondrocytes showed that EGCG ameliorates IL-1 $\beta$-mediated suppression of transforming growth factor $\beta$ synthesis, and enhances type II collagen and aggrecan core protein synthesis in human articular chondrocytes [24]. These results were further supported by a recent study showing the protective effect of EGCG on advanced glycation end productinduced MMP-13 production in human OA chondrocytes in vitro [25].

To further support the chondroprotective effects of EGCG in arthritis, a recent study conducted by the biomaterial testing group on collagen showed that collagen preincubated with EGCG demonstrated a remarkable resistance against degradation by bacterial collagenase and MMP-1 [26]. A circular dichroism spectral analysis of the triple-helical structure of EGCGtreated collagen and untreated collagen showed a higher free-radical scavenging activity in EGCG-treated collagen [26]. Recent studies evaluating the cartilage-preserving property of EGCG showed that articular cartilages, preserved in a storage solution containing EGCG for up to 4 weeks, showed a higher degree of chondrocyte viability and proteoglycan (GAG) content of the extracellular matrix, at least in part, by reversibly regulating the cell cycle at the $G_{0} / G_{1}$ phase and NF- $\mathrm{KB}$ expression $[27,28]$. These findings provide a scientific rationale for the efficacy of EGCG in protecting cartilage breakdown during the progress of joint disorders and could be utilized in other chronic ailments where integrity of the collagen is compromised in tissue destruction or remodeling.

\section{Bone-preserving activity}

In rheumatic diseases, loss of the intricate balance between bone formation and bone resorption activity leads to skeletal abnormalities that affect the quality of life [29]. In particular, three TNF family molecules - the receptor activator of NF-kB, its ligand RANKL, and the decoy receptor of RANKL, osteoprotegerin - have established their pivotal role as central regulators of osteoclast development and osteoclast function [29]. In $2006 \mathrm{Hafeez}$ and colleagues showed that green tea polyphenols triggered caspase-3-dependent apoptosis in these cells by regulating the constitutively active NF-kBp65 to induce DNA fragmentation and apoptosis in osteocarcoma SaOS-2 cells [30]. Another recent study using human osteoblastic cells evaluated the effect of EGCG on oncostatin M-induced monocyte chemotactic protein-1 (MCP-1)/CCL2 synthesis [31]. The experimental findings of the study suggested that EGCG inhibits oncostatin Minduced MCP-1/CCL2 synthesis in human osteoblastic and MG-63 cells by reducing c-Fos synthesis [31].

IL-6 - produced by both stromal cells and osteoblasts in response to several stimuli such as lipopolysaccharides,
IL-1 $\beta$, and TNF $\alpha$ - stimulates bone resorption and osteoclast formation [32,33]. The efficacy of EGCG was evaluated against basic fibroblast growth factor-2induced IL-6 synthesis in osteoblast-like MC3T3-E1 cells [34]. EGCG inhibited basic fibroblast growth factor-2induced IL-6 synthesis dose dependently and, in part, via suppression of ERK1/2 and p38 mitogen-activated protein kinase pathways in osteoblast cells [34]. Further extending these findings, a recent study by Kamon and colleagues showed that EGCG reduced osteoclast formation in these cells by inhibiting osteoblast differentiation without affecting their viability and proliferation [35]. Another recent study addressing the precise molecular mechanism through which EGCG inhibits osteoblast differentiation showed that EGCG produced an anti-osteoclastogenic effect by inhibiting RANKLinduced activation of c-Jun-N-terminal kinase and NF$\mathrm{KB}$ pathways, thereby suppressing the gene expression of c-Fos and NFATc1 in osteoclast precursors [36].

\section{Regulation of synovial fibroblast activity}

Under normal physiological conditions, synovial fibroblasts form a thin lining of synovial tissue surrounded by the fibrous capsule of the joint. The lining of synovial fibroblasts secretes synovial fluid, which has both lubricating and immunomodulatory properties, and which promotes normal joint function. In diseased conditions such as RA, synovial fibroblasts in the RA synovium become hyperproliferative and secrete factors that promote inflammation, neovascularization, and cartilage degradation.

In response to cytokines produced by macrophages such as TNF $\alpha$ and IL-1 $\beta$, RA synovial fibroblasts secrete matrix-degrading enzymes such as MMPs, ADAMTS, and cathepsins. MMPs released from RA synovial fibroblasts can modulate activity of cytokines and chemokines, release proapoptotic ligands from cell surfaces, and promote fibroblast invasion of the cartilage. RA synovial fibroblasts also attract leukocytes by expressing chemokines in response to cytokines via distinct signaling pathway, which provides an opportunity to target them for different therapeutic approaches.

We and other workers have extensively evaluated the efficacy of EGCG using the synovial fibroblasts isolated from human joints to provide the exact mechanism through which EGCG inhibits or suppresses arthritis. Our study showed that EGCG pretreatment significantly inhibited both the constitutive and IL- $1 \beta$-induced chemokine MCP-1/CCL2 production, regulated upon activation, normal T-cell expressed and secreted (RANTES/ CCL5) production, growth-regulated oncogene (Gro- $\alpha /$ CXCL1) production, and epithelial neutrophil-activating peptide 78 (ENA-78/CXCL5) production, and MMP-2 activation by RA synovial fibroblasts [37]. This was 
achieved by EGCG via selective inhibition of the IL-1 $\beta$ induced protein kinase $\mathrm{C} \delta$ and NF-kB pathways. One step further, we found that EGCG significantly inhibited MMP-2 activity induced by RANTES/CCL5, Gro- $\alpha /$ CXCL1, and ENA-78/CXCL5, suggesting a novel mechanism of MMP-2 regulation by EGCG in RA synovial fibroblasts [37]. In our follow-up study, we observed a similar inhibitory effect of EGCG-containing green tea extract (GTE) on chemokine synthesis in RA synovial fibroblasts [38]. GTE preincubation surprisingly induced the basal and IL-1 $\beta$-induced chemokine receptor expression in these cells, however, which was also mimicked by the protein kinase $C \delta$ inhibitor, Rottlerin [38]. Further studies are underway to clarify the significance of these findings in relation to GTE's antiarthritic property.

It has also been shown that EGCG was effective in inhibiting IL-1 $\beta$-induced MMP-1, MMP-3, and MMP-13 in human tendon fibroblasts [39]. Synovial fibroblast IL-6 production has been shown to inhibit bone formation and to concomitantly stimulate bone resorption and pannus formation [40]. In this regard, we showed in our recent study that EGCG pretreatment inhibits IL-1 $\beta$ induced IL-6 and vascular endothelial growth factor synthesis in RA synovial fibroblasts [41]. In a recent study, Yun and colleagues showed that EGCG treatment resulted in dose-dependent inhibition of TNF $\alpha$-induced production of MMP-1 and MMP-3 at the protein and mRNA levels in RA synovial fibroblast by inhibiting activation protein-1 DNA binding activity [42].

In RA, the purposeful induction of apoptosis in activated synovial fibroblasts has emerged as a therapeutic strategy for halting deleterious tissue growth [1]. The constitutive activation of survival protein Akt and NF-kB in RA synovial fibroblasts makes these cells resistant to both TNF $\alpha$-mediated and Fas-mediated apoptosis [43,44]. In recent years, studies have linked the overexpression of the anti-apoptotic myeloid cell leukemia-1 (Mcl-1) protein as a major cause of RA synovial fibroblast resistance to apoptosis $[1,45]$. Our recent study to evaluate the efficacy of EGCG in downregulating Mcl-1 expression showed that, in RA synovial fibroblasts, EGCG inhibits constitutive and TNFo-induced Mcl-1 protein expression [46]. Importantly, EGCG specifically abrogated Mcl-1 expression in RA synovial fibroblasts and affected Mcl-1 expression to a lesser extent in OA synovial fibroblasts, normal synovial fibroblasts, and endothelial cells. In this study, caspase-3 activation by EGCG also suppressed RA synovial fibroblast growth, and this effect was mimicked by Akt and NF- $k B$ inhibitors. Interestingly, Mcl-1 degradation by EGCG sensitized RA synovial fibroblasts to TNF $\alpha$ induced cleavage of poly ADP-ribose polymerase protein and apoptosis. Our finding suggests that EGCG may selectively induce apoptosis and further sensitize RA synovial fibroblasts to TNF $\alpha$-induced apoptosis to regulate their invasive growth in RA.

\section{Animal studies \\ Collagen-induced arthritis}

The potential disease-modifying effect of EGCG on arthritis was first discovered in a study in which the consumption of EGCG-containing GTE in drinking water ameliorated collagen-induced arthritis (CIA) in mice [47]. The reduced CIA incidence and severity was reflected in a marked inhibition of the inflammatory mediators COX-2, IFN $\gamma$, and TNF $\alpha$ in arthritic joints of green tea-fed mice. Additionally, total immunoglobulins (IgG) and type II collagen-specific IgG levels were found to be lower in serum and arthritic joints of green tea-fed mice [47].

Interestingly, some recent pharmacological studies using EGCG or green tea to suppress arthritis have focused equally on bone resorption observed in RA [31,48-51]. A recent study by Morinobu and colleagues showed that EGCG treatment reduced bone resorption as determined by tartrate-resistant acid phosphatasepositive multinucleated cells, bone resorption activity, and osteoblast-specific gene expression of the transcription factor NF-ATc1, but not of NF-kB, c-Fos, and c-Jun [49]. The in vivo effect of osteoclast differentiation in CIA mice was not clear, however, as intraperitoneal administration of EGCG $(20 \mathrm{mg} / \mathrm{kg})$ inhibited inflammation in experimental arthritis [49]. Using in vivo testing conducted in mouse CIA model, another study showed that EGCG $(20 \mathrm{mg} / \mathrm{kg}$, intraperitoneally daily) ameliorated arthritis and macrophage infiltration, and caused a reduction in the amount of MCP-1/CCL2-synthesizing osteoblasts [31].

\section{Adjuvant-induced arthritis}

Recent advances in understanding the pathogenic effects of IL-6 provide evidence of its central role in promoting acute inflammation $[32,33]$. Further studies related to the mechanisms through which EGCG inhibits inflammation and tissue destruction in RA were studied by us and others. Our novel findings showed that EGCG selectively inhibits IL-6 synthesis in rat adjuvant-induced arthritis, thus providing a missing link to the reduction in inflammation observed in earlier studies [41]. Administration of EGCG $(100 \mathrm{mg} / \mathrm{kg}$, intraperitoneally daily) during the onset of arthritis in rats resulted in a specific inhibition of IL-6 levels in the serum and joints of EGCG-treated animals. Our study also showed that EGCG enhances the synthesis of soluble gp130 protein, an endogenous inhibitor of IL-6 signaling and trans-signaling [41]. The inhibition of arthritis in EGCG-treated rats correlated to the reduction in MMP-2 activity in the joints compared with the activity level in arthritic rats [41]. 
A recent study testing a possible immunomodulatory activity of GTE in arthritis showed that GTE administration in drinking water ameliorated rat adjuvantinduced arthritis via the inhibition of serum IL-17 levels, with a concomitant upregulation of serum IL-10 levels [52]. In our recent study, a daily per oral administration of GTE $(200 \mathrm{mg} / \mathrm{kg})$ modestly ameliorated rat adjuvantinduced arthritis, which was accompanied by a decrease in MCP-1/CCL2 and GROo/CXCL1 levels and enhanced CCR-1, CCR-2, CCR-5, and CXCR1 receptor expression in the joints of GTE-administered rats [38]. This suggests that chemokine receptor overexpression with reduced chemokine production by GTE may be one potential mechanism to limit the overall inflammation and joint destruction in RA. Further studies may be designed to improve the clinical outcome in animal models of RA through modification of the dose and frequency of GTE administration, which may provide a better outcome and benefits of GTE in RA.

\section{Clinical studies}

The efficacy of EGCG or GTE in human RA or OA using the phase-controlled trials is yet to be tested. Several phase I and phase II cancer chemoprevention trials, however, have been performed using EGCG or GTE. A study by Elmets and colleagues showed that EGCG provided photoprotection to the skin from ultraviolet radiation on topical application in healthy human volunteers [53]. In another study, patients suffering from chronic lymphocytic leukemia showed an improvement in their clinical, laboratory, and radiographic outcomes and objective responses [54] after oral ingestion of EGCG. The results of a recent open-label, phase II clinical trial using EGCG in prostate cancer patients showed a significant decrease in the serum levels of prostate-specific antigen, hepatocyte growth factor, and vascular endothelial growth factor after 6 weeks of treatment [55]. A phase I trial on EGCG, with a 400 to 2,000 mg dose taken by mouth twice a day for month, was well tolerated by chronic lymphocytic leukemia patients, the majority of whom showed a decline in lymphocyte count and lymphadenopathy [56]. This has encouraged the investigators of the study to initiate a phase II trial to evaluate EGCG efficacy using a 2,000 mg dose twice daily [56].

The efficacy of EGCG in human metabolic disorders has been a topic of clinical interest. A randomized, controlled clinical trial using EGCG on insulin resistance and associated metabolic risk factors in obese men showed that $400 \mathrm{mg}$ EGCG treatment twice daily for 8 weeks showed no effect on insulin sensitivity or secretion and glucose tolerance, but caused a moderate reduction in blood pressure and a positive effect on mood [57]. In another study by Maki and colleagues, the consumption of $625 \mathrm{mg}$ EGCG-containing catechins daily for 12 weeks caused a greater loss of body weight and a decrease in the fasting serum triglyceride levels in the catechin-administered group [58]. In a double-blind, placebo-controlled trial, intake of GTE (containing 302 mg EGCG) for 12 weeks showed a significant reduction in the levels of low-density lipoprotein and triglyceride, and markedly increased the high-density lipoproteins and adiponectin levels [59].

\section{EGCG: bioavailability and possible drug interactions}

\section{Pharmacokinetics of EGCG}

The pharmacokinetics and bioavailability of EGCG in rodents and humans is well studied. An acute and shortterm toxicity study on EGCG preparations showed that the dietary consumption of EGCG by rats for 13 weeks was nontoxic at doses up to $500 \mathrm{mg} / \mathrm{kg} /$ day [60]. A study by Chen and colleagues showed that administration of pure EGCG or EGCG in the form of decaffeinated GTE to rats via intravenous or intragastric administration showed differences in the pharmacokinetic patterns, favoring the intravenous route when given as an extract [61]. Studies also revealed that EGCG possesses a longer half-life and a smaller clearance rate, suggesting a slower rate of elimination of EGCG as compared with epigallocatechin and epicatechin [61]. A study by Kim and colleagues, in which subjects consumed GTE at $0.6 \%$ in drinking water over 28 days, showed that EGCG is more available in free form as compared with other catechins [62]. These studies also showed that the highest concentration of EGCG was found in the large intestine, suggesting a higher absorption rate but less clearance as demonstrated by the lower levels of EGCG detected in plasma and distributed in the kidney, liver, lungs, and prostate of rats $[61,62]$. In contrast to the results with rats, however, the level of EGCG in mice was much higher than that of epigallocatechin and epicatechin, suggesting a high bioavailability of EGCG in mice [62]. In addition, it was reported that the intraperitoneal administration of green tea containing EGCG showed much higher tissue and plasma concentration of EGCG than that obtained intragastrically [62]. Although other chemical processes such as peracetylation and glucuronidation have been shown to enhance the bioavailability of EGCG, not much is known about the distribution and its bioactivity in diseased conditions.

In humans, EGCG has been extensively studied for its acute and long-term toxicity studies [63-66]. A standardized capsule of polyphenon E containing $400 \mathrm{mg}, 800 \mathrm{mg}$, or 1,200 mg EGCG was used to study the pharmacokinetics of EGCG in humans [63,64]. The pharmacokinetic analysis from the study showed that the average plasma area under the curve, the maximum concentration, and 
the half-life increased with an increase in the dosages given in the capsules of $400 \mathrm{mg}, 800 \mathrm{mg}$, and 1,200 mg EGCG [64]. This study also showed that administration of EGCG capsules to human subjects under fasting conditions significantly enhanced the pharmacokinetic profile and bioavailability of EGCG, possibly due to reduced conversion by glucuronidation process [64]. A 4-week clinical study carried out to determine the safety and pharmacokinetics of EGCG at doses of 400 and $800 \mathrm{mg} /$ day in healthy participants showed no significant adverse effects, and investigators observed a significant $(>60 \%)$ increase in EGCG bioavailability by the $800 \mathrm{mg} /$ day dose, when compared with the $400 \mathrm{mg} /$ day dose, in these participants [63]. There are, however, limited numbers of studies suggesting that the EGCG plasma concentration may reach up to $\sim 1 \mu \mathrm{M}$ when consumed by drinking green tea $[67,68]$. Further studies are required to optimize the circulating and synovial concentrations of EGCG to avail benefits similar to those observed in vitro and in preclinical studies.

\section{Drug interaction}

There have been limited data available to validate or reject the potential benefit of EGCG in RA patients. Studies conducted recently, however, evaluate the efficacy of EGCG in combination with conventional medicine, which could be extrapolated for possible interaction with anti-rheumatic drugs. The initial observation came from the anti-cancer studies using EGCG, wherein the administration of EGCG was shown to enhance the apoptosis-inducing property of COX-2 inhibitors on the growth of human prostate cancer cells in vitro and in vivo [69]. In another related study, EGCG sensitized human prostate carcinoma LNCaP cells to TNF-related apoptosisinducing ligand-induced apoptosis and synergistic inhibition of the biomarkers of angiogenesis and metastasis [70]. Similar outcomes on the sensitization of RA synovial fibroblasts for TNF-related apoptosis-inducing ligand-induced apoptosis were observed with trichostatin A, suggesting a common mechanism of regulating invasive growth of synovial tissue in RA [71].

Another unique mechanism through which EGCG leaves a positive impact as a potential therapeutic option comes from its property of inducing pretranscriptional modification, termed alternative splicing. In addition to our study, where EGCG enhanced the synthesis of soluble gp130 at least in part by this mechanism, recent reports suggest that EGCG modulates alternative splicing to correct mutated proteins to normal forms, as observed for survival motor neuron-1 protein in neurodegenerative disorder, or to produce spliced variants of Mcl-1 and Bcl$\mathrm{X}$ proteins in combination with ibuprofen that may inhibit the functionality of these anti-apoptotic proteins in prostate cancer cells [41,72,73]. More recently, conflicting results have emerged from the studies related to the effect of EGCG on clinical efficacy of the chemotherapeutic agent Bortezomib as a proteasome inhibitor in cancer-related studies [74,75]. More elaborative and rigorous studies are awaited, however, to verify the possible interaction of EGCG with current treatment modalities for rheumatic diseases - in particular, biological therapies and methotrexate treatment.

\section{Development of synthetic analogs of EGCG: future implications}

The growing interest of pharmacologists in studying EGCG was never hidden from medicinal chemists, which led to the development of synthetic analogs of EGCG [76]. Zaveri and colleagues reported the synthesis of a trimethoxybenzoyl ester (D-ring) analog of EGCG, which was found to be equally as potent as natural EGCG for its efficacy as an anti-carcinogenic agent [77]. In addition, there have been some recent efforts to enhance its bioavailability by delivering EGCG using lipid nanocapsules and liposome encapsulation, suggesting the possibility of this molecule being developed further by medicinal chemists [78]. In this direction, there has been a successful in vitro and in vivo testing of delivering EGCG in polylactic acid-polyethylene glycol nanoparticles to inhibit angiogenesis and induce apoptosis [79]. Similarly, the results from a recent study suggest that nanolipidic EGCG particles significantly improved the neuronal $\alpha$-secretase enhancing ability and possessed the oral bioavailability more than twofold over free EGCG for the treatment of Alzheimer's disease [80].

\section{Conclusions and future implications}

The present review summarizes the translational research for the validation of the purported benefits of EGCG in preclinical and clinical settings. An extensive evaluation of the potential risks or benefits of using EGCG alone or together with anti-rheumatic drugs may open a new area of research wherein EGCG or its synthetic analogs could be developed to enhance its clinical appeal. Extensive research on the benefits of EGCG in other chronic ailments such as carcinogenesis and cardiovascular diseases using clinical trials has shown promise $[81,82]$. With the availability of the safety profile and pharmacokinetics of EGCG in phase I trials in humans, the window of opportunity is even wider to test EGCG for its potential therapeutic efficacy as an anti-rheumatic entity in human RA or OA. In conclusion, for the scientists and clinicians in the research area of drug discovery, EGCG represents a much safer molecule worth testing in humans, as the positive outcomes of such studies may have potential for its rapid clinical development and application. 


\section{Abbreviations}

ADAMTS, a disintegrin-like and metalloprotease domain with thrombospondin type I motifs; CIA, collagen-induced arthritis; COX-2, cyclooxygenase-2; EGCG, epigallocatechin-3-gallate; ENA-78, epithelial neutrophil-activating peptide 78; GRO-a, growth regulated oncogene-a; GTE, EGCG-containing green tea extract; IFN, interferon; IL, interleukin; Mcl-1, myeloid cell leukemia-1; MCP-1, monocyte chemotactic protein-1; MMP, matrix metalloproteinase; NF, nuclear factor; NF-ATc1, nuclear factor of activated T cells; OA, osteoarthritis; RA, rheumatoid arthritis; RANKL, receptor activator of NF-KB ligand; RANTES, regulated upon activation, normal T-cell expressed and secreted; TNF, tumor necrosis factor.

\section{Competing interests}

The author declares that he has no competing interests.

\section{Acknowledgements}

The present work was supported in part by the NIH grants AT-003633 and AR-055741, and the start-up funds from The University of Toledo. The author thanks Ms Charisse N Montgomery for critical reading of the review.

Published: 28 April 2010

\section{References}

1. Pope RM: Apoptosis as a therapeutic tool in rheumatoid arthritis. Nat Rev Immunol 2002, 2:527-535.

2. Feldmann M, Maini SR: Role of cytokines in rheumatoid arthritis: an education in pathophysiology and therapeutics. Immunol Rev 2008 223:7-19.

3. Samuels J, Krasnokutsky S, Abramson SB: Osteoarthritis: a tale of three tissues. Bull NYU Hosp Jt Dis 2008, 66:244-250.

4. Malemud CJ, Islam N, Haqqi TM: Pathophysiological mechanisms in osteoarthritis lead to novel therapeutic strategies. Cells Tissues Organs 2003, 174:34-48.

5. Siddiqui MA: The efficacy and tolerability of newer biologics in rheumatoid arthritis: best current evidence. Cur Opin Rheumato/ 2007, 19:308-313.

6. van Vollenhoven RF: Treatment of rheumatoid arthritis: state of the art 2009. Nat Rev Rheumato/ 2009, 5:531-541.

7. Fox BA, Stephens MM: Glucosamine/chondroitin/primorine combination therapy for osteoarthritis. Drugs Today (Barc) 2009, 45:21-31

8. Felson DT: Developments in the clinical understanding of osteoarthritis. Arthritis Res Ther 2009, 11:203

9. Callahan LF, Wiley-Exley EK, Mielenz TJ, Brady TJ, Xiao C, Currey SS, Sleath BL, Sloane PD, DeVellis RF, Sniezek J: Use of complementary and alternative medicine among patients with arthritis. Prev Chronic Dis 2009, 6:A44

10. Kikuchi M, Matsuura K, Matsumoto Y, Inagaki T, Ueda R: Bibliographical investigation of complementary alternative medicines for osteoarthritis and rheumatoid arthritis. Geriatr Gerontol Int 2009, 9:29-40.

11. Marcus DM: Therapy: herbals and supplements for rheumatic diseases. Nat Rev Rheumatol 2009, 5:299-300.

12. Manning J, Roberts JC: Analysis of catechin content of commercial green tea products. J Herbal Pharmacother 2003, 3:19-32.

13. Doss MX, Potta SP, Hescheler J, Sachinidis A: Trapping of growth factors by catechins: a possible therapeutical target for prevention of proliferative diseases. J Nutr Biochem 2005, 16:259-266.

14. Cooper R, Morre DJ, Morre DM: Medicinal benefits of green tea: part I. Review of noncancer health benefits. J Alter Complement Med 2005, 11:521-528.

15. Ahmed S, Rahman A, Hasnain A, Lalonde M, Goldberg VM, Haqqi TM: Green tea polyphenol epigallocatechin-3-gallate inhibits the IL-1 beta-induced activity and expression of cyclooxygenase- 2 and nitric oxide synthase- 2 in human chondrocytes. Free Radic Biol Med 2002, 33:1097-1105.

16. Singh R, Ahmed S, Islam N, Goldberg VM, Haqqi TM: Epigallocatechin-3gallate inhibits interleukin-1 $\beta$-induced expression of nitric oxide synthase and production of nitric oxide in human chondrocytes: suppression of nuclear factor $\mathrm{KB}$ activation by degradation of the inhibitor of nuclear factor KB. Arthritis Rheum 2002, 46:2079-2086.

17. Singh R, Ahmed S, Malemud CJ, Goldberg VM, Haqqi TM: Epigallocatechin-3gallate selectively inhibits interleukin-1 beta-induced activation of mitogen activated protein kinase subgroup c-Jun $\mathrm{N}$-terminal kinase in human osteoarthritis chondrocytes. J Orthop Res 2003, 21:102-109.

18. Brinckerhoff CE, Matrisian LM: Matrix metalloproteinases: a tail of a frog that became a prince. Nat Rev Mol Cell Bio/ 2002, 3:207-214

19. Dahlberg L, Billinghurst RC, Manner P, Nelson F, Webb G, lonescu M, Reiner A, Tanzer M, Zukor D, Chen J, van Wart HE, Poole AR: Selective enhancement of collagenase-mediated cleavage of resident type II collagen in cultured osteoarthritic cartilage and arrest with a synthetic inhibitor that spares collagenase 1 (matrix metalloproteinase 1). Arthritis Rheum 2000, 43:673-682.

20. Mitchell PG, Magna HA, Reeves LM, Lopresti-Morrow LL, Yocum SA, Rosner PJ Geoghegan KF, Hambor JE: Cloning, expression, and type II collagenolytic activity of matrix metalloproteinase-13 from human osteoarthritic cartilage. J Clin Invest 1996, 97:761-768.

21. Ahmed S, Wang N, Lalonde M, Goldberg VM, Haqqi TM: Green tea polyphenol epigallocatechin-3-gallate (EGCG) differentially inhibits interleukin-1 beta-induced expression of matrix metalloproteinase-1 and -13 in human chondrocytes. J Pharmacol Exp Ther 2004, 308:767-773.

22. Adcocks C, Collin P, Buttle DJ: Catechins from green tea (Camellia sinensis) inhibit bovine and human cartilage proteoglycan and type II collagen degradation in vitro. J Nutr 2002, 132:341-346.

23. Vankemmelbeke MN, Jones GC, Fowles C, Ilic MZ, Handley CJ, Day AJ, Knight CG, Mort JS, Buttle DJ: Selective inhibition of ADAMTS- $1,-4$ and -5 by catechin gallate esters. Eur J Biochem 2003, 270:2394-2403.

24. Andriamanalijaona R, Kypriotou M, Bauge C, Renard E, Legendre F, Raoudi M, Boumediene K, Gatto H, Monginoux P, Pujol JP: Comparative effects of 2 antioxidants, selenomethionine and epigallocatechin-gallate, on catabolic and anabolic gene expression of articular chondrocytes. J Rheumato/ 2005, 32:1958-1967.

25. Rasheed Z, Anbazhagan AN, Akhtar N, Ramamurthy S, Voss FR, Haqqi TM: Green tea polyphenol epigallocatechin-3-gallate inhibits advanced glycation end product-induced expression of tumor necrosis factor-alpha and matrix metalloproteinase-13 in human chondrocytes. Arthritis Res Ther 2009, 11:R71.

26. Goo HC, Hwang YS, Choi YR, Cho HN, Suh H: Development of collagenaseresistant collagen and its interaction with adult human dermal fibroblasts. Biomaterials 2003, 24:5099-5113.

27. Bae JY, Matsumura K, Wakitani S, Kawaguchi A, Tsutsumi S, Hyon SH: Beneficial storage effects of epigallocatechin-3-o-gallate on the articular cartilage of rabbit osteochondral allografts. Cell Transplant 2009, 18:505-512.

28. Han DW, Bae JY, Matsumura K, Wakitani S, Nawata M, Hyon SH: Non-frozen preservation of articular cartilage by epigallocatechin-3-gallate reversibly regulating cell cycle and NF-kB expression. Tissue Eng Part A 2009 [Epub ahead of print].

29. Leibbrandt A, Penninger JM: RANK/RANKL: regulators of immune responses and bone physiology. Ann N Y Acad Sci 2008, 1143:123-150.

30. Hafeez BB, Ahmed S, Wang N, Gupta S, Zhang A, Haqqi TM: Green tea polyphenols-induced apoptosis in human osteosarcoma SAOS-2 cells involves a caspase-dependent mechanism with downregulation of nuclear factor-kB. Toxicol Appl Pharmacol 2006, 216:11-19.

31. Lin SK, Chang HH, Chen YJ, Wang CC, Galson DL, Hong CY, Kok SH: Epigallocatechin-3-gallate diminishes CCL2 expression in human osteoblastic cells via up-regulation of phosphatidylinositol 3-Kinase/Akt/ Raf-1 interaction: a potential therapeutic benefit for arthritis. Arthritis Rheum 2008, 58:3145-3156.

32. Kishimoto T: IL-6: from laboratory to bedside. Clin Rev Allergy Immuno/ 2005 28:177-186.

33. Nishimoto N: Interleukin-6 in rheumatoid arthritis. Curr Opin Rheumatol 2006, 18:277-281.

34. Tokuda H, Takai S, Hanai Y, Matsushima-Nishiwaki R, Hosoi T, Harada A, Ohta T, Kozawa O: (-)-Epigallocatechin gallate suppresses endothelin-1-induced interleukin- 6 synthesis in osteoblasts: inhibition of p44/p42 MAP kinase activation. FEBS Lett 2007, 581:1311-1316

35. Kamon M, Zhao R, Sakamoto K: Green tea polyphenol (-)-epigallocatechin gallate suppressed the differentiation of murine osteoblast MC3T3-E1 cell. Cell Biol Int 2009, 34:109-116.

36. Lee JH, Jin H, Shim HE, Kim HN, Ha H, Lee ZH: Epigallocatechin-3-gallate inhibits osteoclastogenesis by down-regulating c-Fos expression and suppressing the NF-KB signal. Mol Pharmacol 2010, 77:17-25.

37. Ahmed S, Pakozdi A, Koch AE: Regulation of interleukin-1 $\beta$-induced chemokine production and matrix metalloproteinase 2 activation by epigallocatechin-3-gallate in rheumatoid arthritis synovial fibroblasts. Arthritis Rheum 2006, 54:2393-2401. 
38. Marotte H, Ruth JH, Campbell PL, Koch AE, Ahmed S: Green tea extract inhibits chemokine production, but up-regulates chemokine receptor expression, in rheumatoid arthritis synovial fibroblasts and rat adjuvantinduced arthritis. Rheumatology (Oxford) 2010, 49:467-479

39. Corps AN, Curry VA, Buttle DJ, Hazleman BL, Riley GP: Inhibition of interleukin-1 $\beta$-stimulated collagenase and stromelysin expression in human tendon fibroblasts by epigallocatechin gallate ester. Matrix Biol 2004, 23:163-169.

40. Cronstein BN: Interleukin-6 - a key mediator of systemic and local symptoms in rheumatoid arthritis. Bull NYU Hosp Jt Dis 2007, 65(Suppl 1):S11-S15.

41. Ahmed S, Marotte H, Kwan K, Ruth JH, Campbell PL, Rabquer BJ, Pakozdi A, Koch AE: Epigallocatechin-3-gallate inhibits IL-6 synthesis and suppresses transsignaling by enhancing soluble gp130 production. Proc Natl Acad SC USA 2008, 105:14692-14697.

42. Yun HJ, Yoo WH, Han MK, Lee YR, Kim JS, Lee SI: Epigallocatechin-3-gallate suppresses TNF- $a$-induced production of MMP-1 and -3 in rheumatoid arthritis synovial fibroblasts. Rheumatol Int 2008, 29:23-29.

43. Zhang HG, Huang N, Liu D, Bilbao L, Zhang X, Yang P, Zhou T, Curiel DT, Mountz JD: Gene therapy that inhibits nuclear translocation of nuclear factor $\mathrm{KB}$ results in tumor necrosis factor alpha-induced apoptosis of human synovial fibroblasts. Arthritis Rheum 2000, 43:1094-1105.

44. Zhang HG, Wang Y, Xie JF, Liang X, Liu D, Yang P, Hsu HC, Ray RB, Mountz JD: Regulation of tumor necrosis factor alpha-mediated apoptosis of rheumatoid arthritis synovial fibroblasts by the protein kinase Akt. Arthritis Rheum 2001, 44:1555-1567.

45. Liu H, Eksarko P, Temkin V, Haines GK, 3rd, Perlman H, Koch AE, Thimmapaya B, Pope RM: Mcl-1 is essential for the survival of synovial fibroblasts in rheumatoid arthritis. J Immuno/ 2005, 175:8337-8345.

46. Ahmed S, Silverman MD, Marotte H, Kwan K, Matuszczak N, Koch AE: Downregulation of myeloid cell leukemia 1 by epigallocatechin-3-gallate sensitizes rheumatoid arthritis synovial fibroblasts to tumor necrosis factor alpha-induced apoptosis. Arthritis Rheum 2009, 60:1282-1293.

47. Haqqi TM, Anthony DD, Gupta S, Ahmad N, Lee MS, Kumar GK, Mukhtar H: Prevention of collagen-induced arthritis in mice by a polyphenolic fraction from green tea. Proc Natl Acad Sci U SA 1999, 96:4524-4529.

48. Lin RW, Chen CH, Wang YH, Ho ML, Hung SH, Chen IS, Wang GJ: (-)-Epigallocatechin gallate inhibition of osteoclastic differentiation via NF-kB. Biochem Biophys Res Commun 2009, 379:1033-1037.

49. Morinobu A, Biao W, Tanaka S, Horiuchi M, Jun L, Tsuji G, Sakai Y, Kurosaka M, Kumagai S: (-)-Epigallocatechin-3-gallate suppresses osteoclast differentiation and ameliorates experimental arthritis in mice. Arthritis Rheum 2008, 58:2012-2018.

50. Natsume H, Adachi S, Takai S, Tokuda H, Matsushima-Nishiwaki R, Minamitani C, Yamauchi J, Kato K, Mizutani J, Kozawa O, Otsuka T: (-)-Epigallocatechin gallate attenuates the induction of HSP27 stimulated by sphingosine 1-phosphate via suppression of phosphatidylinositol 3-kinase/Akt pathway in osteoblasts. Int J Mol Med 2009, 24:197-203.

51. Takai S, Matsushima-Nishiwaki R, Adachi S, Natsume H, Minamitani C, Mizutani J, Otsuka T, Tokuda H, Kozawa O: (-)-Epigallocatechin gallate reduces platelet-derived growth factor-BB-stimulated interleukin-6 synthesis in osteoblasts: suppression of SAPK/JNK. Mediators Inflamm 2008, 2008:291808.

52. Kim HR, Rajaiah R, Wu QL, Satpute SR, Tan MT, Simon JE, Berman BM, Moudgil $\mathrm{KD}$ : Green tea protects rats against autoimmune arthritis by modulating disease-related immune events. J Nutr 2008, 138:2111-2116.

53. Elmets CA, Singh D, Tubesing K, Matsui M, Katiyar S, Mukhtar H: Cutaneous photoprotection from ultraviolet injury by green tea polyphenols. J Am Acad Dermatol 2001, 44:425-432.

54. Shanafelt TD, Lee YK, Call TG, Nowakowski GS, Dingli D, Zent CS, Kay NE: Clinical effects of oral green tea extracts in four patients with low grade B-cell malignancies. Leuk Res 2006, 30:707-712

55. McLarty J, Bigelow RL, Smith M, Elmajian D, Ankem M, Cardelli JA: Tea polyphenols decrease serum levels of prostate-specific antigen, hepatocyte growth factor, and vascular endothelial growth factor in prostate cancer patients and inhibit production of hepatocyte growth factor and vascular endothelial growth factor in vitro. Cancer Prev Res 2009, 2:673-682.

56. Shanafelt TD, Call TG, Zent CS, LaPlant B, Bowen DA, Roos M, Secreto CR, Ghosh AK, Kabat BF, Lee MJ, Yang CS, Jelinek DF, Erlichman C, Kay NE: Phase I trial of daily oral polyphenon $\mathrm{E}$ in patients with asymptomatic Rai stage 0 to II chronic lymphocytic leukemia. J Clin Onco/ 2009, 27:3808-3814.

57. Brown AL, Lane J, Coverly J, Stocks J, Jackson S, Stephen A, Bluck L, Coward A, Hendrickx H: Effects of dietary supplementation with the green tea polyphenol epigallocatechin-3-gallate on insulin resistance and associated metabolic risk factors: randomized controlled trial. $\mathrm{Br} J \mathrm{Nutr}$ 2009, 101:886-894.

58. Maki KC, Reeves MS, Farmer M, Yasunaga K, Matsuo N, Katsuragi Y, Komikado M, Tokimitsu I, Wilder D, Jones F, Blumberg JB, Cartwright Y: Green tea catechin consumption enhances exercise-induced abdominal fat loss in overweight and obese adults. J Nutr 2009, 139:264-270.

59. Hsu CH, Tsai TH, Kao YH, Hwang KC, Tseng TY, Chou P: Effect of green tea extract on obese women: a randomized, double-blind, placebo-controlled clinical trial. Clin Nutr 2008, 27:363-370.

60. Isbrucker RA, Edwards JA, Wolz E, Davidovich A, Bausch J: Safety studies on epigallocatechin gallate (EGCG) preparations. Part 2: dermal, acute and short-term toxicity studies. Food Chem Toxicol 2006, 44:636-650.

61. Chen L, Lee MJ, Li H, Yang CS: Absorption, distribution, elimination of tea polyphenols in rats. Drug Metab Dispos 1997, 25:1045-1050.

62. Kim S, Lee MJ, Hong J, Li C, Smith TJ, Yang GY, Seril DN, Yang CS: Plasma and tissue levels of tea catechins in rats and mice during chronic consumption of green tea polyphenols. Nutr Cancer 2000, 37:41-48.

63. Chow HH, Cai Y, Hakim IA, Crowell JA, Shahi F, Brooks CA, Dorr RT, Hara Y, Alberts DS: Pharmacokinetics and safety of green tea polyphenols after multiple-dose administration of epigallocatechin gallate and polyphenon E in healthy individuals. Clin Cancer Res 2003, 9:3312-3319.

64. Chow HH, Hakim IA, Vining DR, Crowell JA, Ranger-Moore J, Chew WM, Celaya CA, Rodney SR, Hara Y, Alberts DS: Effects of dosing condition on the oral bioavailability of green tea catechins after single-dose administration of polyphenon E in healthy individuals. Clin Cancer Res 2005, 11:4627-4633.

65. Manach C, Williamson G, Morand C, Scalbert A, Remesy C: Bioavailability and bioefficacy of polyphenols in humans. I. Review of 97 bioavailability studies. Am J Clin Nutr 2005, 81(1 Suppl):230S-242S.

66. Williamson G, Manach C: Bioavailability and bioefficacy of polyphenols in humans. II. Review of 93 intervention studies. Am J Clin Nutr 2005, 81(1 Suppl):243S-255S.

67. Umegaki K, Sugisawa A, Yamada K, Higuchi M: Analytical method of measuring tea catechins in human plasma by solid-phase extraction and HPLC with electrochemical detection. J Nutr Sci Vitaminol 2001, 47:402-408

68. Yang CS, Chen L, Lee MJ, Balentine D, Kuo MC, Schantz SP: Blood and urine levels of tea catechins after ingestion of different amounts of green tea by human volunteers. Cancer Epidemiol Biomarkers Prev 1998, 7:351-354.

69. Adhami VM, Malik A, Zaman N, Sarfaraz S, Siddiqui IA, Syed DN, Afaq F, Pasha FS, Saleem M, Mukhtar H: Combined inhibitory effects of green tea polyphenols and selective cyclooxygenase-2 inhibitors on the growth of human prostate cancer cells both in vitro and in vivo. Clin Cancer Res 2007, 13:1611-1619.

70. Siddiqui IA, Malik A, Adhami VM, Asim M, Hafeez BB, Sarfaraz S, Mukhtar H: Green tea polyphenol EGCG sensitizes human prostate carcinoma LNCaP cells to TRAIL-mediated apoptosis and synergistically inhibits biomarkers associated with angiogenesis and metastasis. Oncogene 2008 27:2055-2063.

71. Jungel A, Baresova V, Ospelt C, Simmen BR, Michel BA, Gay RE, Gay S, Seemayer CA, Neidhart M: Trichostatin A sensitises rheumatoid arthritis synovial fibroblasts for TRAIL-induced apoptosis. Ann Rheum Dis 2006, 65:910-912.

72. Kim MH: Protein phosphatase 1 activation and alternative splicing of $\mathrm{BCl}-\mathrm{X}$ and Mcl-1 by EGCG + ibuprofen. J Cell Biochem 2008, 104:1491-1499.

73. Sakla MS, Lorson CL: Induction of full-length survival motor neuron by polyphenol botanical compounds. Hum Genet 2008, 122:635-643.

74. Golden EB, Lam PY, Kardosh A, Gaffney KJ, Cadenas E, Louie SG, Petasis NA Chen TC, Schonthal AH: Green tea polyphenols block the anticancer effects of bortezomib and other boronic acid-based proteasome inhibitors. Blood 2009, 113:5927-5937

75. Yang H, Zonder JA, Dou QP: Clinical development of novel proteasome inhibitors for cancer treatment. Expert Opin Investig Drugs 2009, 18:957-971.

76. Zaveri NT: Synthesis of a 3,4,5-trimethoxybenzoyl ester analogue of epigallocatechin-3-gallate (EGCG): a potential route to the natural product green tea catechin, EGCG. Org Lett 2001, 3:843-846.

77. Waleh NS, Chao WR, Bensari A, Zaveri NT: Novel D-ring analog of epigallocatechin-3-gallate inhibits tumor growth and VEGF expression in breast carcinoma cells. Anticancer Res 2005, 25:397-402. 
78. Barras A, Mezzetti A, Richard A, Lazzaroni S, Roux S, Melnyk P, Betbeder D, Monfilliette-Dupont N: Formulation and characterization of polyphenolloaded lipid nanocapsules. Int J Pharm 2009, 379:270-277.

79. Siddiqui IA, Adhami VM, Bharali DJ, Hafeez BB, Asim M, Khwaja SI, Ahmad N, Cui H, Mousa SA, Mukhtar H: Introducing nanochemoprevention as a novel approach for cancer control: proof of principle with green tea polyphenol epigallocatechin-3-gallate. Cancer Res 2009, 69:1712-1716.

80. Smith A, Giunta B, Bickford PC, Fountain M, Tan J, Shytle RD: Nanolipidic particles improve the bioavailability and alpha-secretase inducing ability of epigallocatechin-3-gallate (EGCG) for the treatment of Alzheimer's disease. Int J Pharm, 389:207-212
81. Boschmann M, Thielecke F: The effects of epigallocatechin-3-gallate on thermogenesis and fat oxidation in obese men: a pilot study. J Am Coll Nutr 2007, 26:389S-395S.

82. Carlson JR, Bauer BA, Vincent A, Limburg PJ, Wilson T: Reading the tea leaves: anticarcinogenic properties of (-)-epigallocatechin-3-gallate. Mayo Clin Proc 2007, 82:725-732.

doi:10.1186/ar2982

Cite this article as: Ahmed S: Green tea polyphenol epigallocatechin 3-gallate in arthritis: progress and promise. Arthritis Research \& Therapy 2010, $12: 208$. 